\title{
CONF-960468-1
}

SAND95- $2865 C$

\section{Characterization and Assessment of HTML Style Guides}

\author{
Julie Ratner, Eric M. Grose \& Chris Forsythe \\ Statistics and Human Factors \\ Sandia National Laboratories \\ Albuquerque, NM USA \\ E-mail: jratner@sandia.gov
}

\begin{abstract}
This paper describes a study in which HTML style guides were characterized, compared to established $\mathrm{HCl}$ style guides, and evaluated against findings from $\mathrm{HCI}$ reviews of web pages and applications. Findings showed little consistency among the 21 HTML style guides assessed, with $75 \%$ of recommendations appearing in only one style guide. While there was some overlap, only $20 \%$ of HTML relevant recommendations from established style guides were found in HTML style guides. HTML style guides emphasized common look and feel, information display, and navigation issues with little mention of many issues prominent in established style guides such as help, message boxes and data entry. This difference is reinforced by other results showing that HTML style guides addressed concerns of web information content pages with much greater success than web-based applications. It is concluded that while the WWW represents a unique HCI environment, development of HTML style guides has been less rigorous, with issues associated with web-based applications largely ignored.
\end{abstract}

KEYWORDS: HTML, World Wide Web, Style Guides, Human Computer Interface

\section{INTRODUCTION}

The popularity and prolific expansion of the World Wide Web (WWW) has fueled an unprecedented growth in the number of developers creating computer-based materials for public access[2]. Hypertext Markup Language (HTML) has been the predominant language used by WWW developers. In the brief existence of the WWW, there has not been an opportunity for style guides and conventions comparable to other Human Computer Interface $(\mathrm{HCl})$ domains to first, be developed and secondly, gain acceptance from the development community, concerns with the effectiveness of style guides aside $[1,3,4]$. This predicament is worsened by HTML developers with limited knowledge of traditional HCI concerns and a general unfamiliarity of many problems raised by cross-platform and browser compatibility requirements faced with WWW-based HCIs. To fill these voids, numerous $\mathrm{HCl}$ style guides have appeared for HTML development. This paper provides a general characterization of internet-accessible $\mathrm{HCl}$ style guides for HTML, a comparison of HTML and established $\mathrm{HCI}$ style guides, and an assessment of HTML style guides based on findings from usability assessments of HTML-based interfaces.

\section{SAMPLING}

The intent of this study was to assess the collective knowledge regarding $\mathrm{HCI}$ style components and not to evaluate individual style guides. Thus, HTML style guides were combined to form a single, comprehensive set of $\mathrm{HCI}$ style recommendations. Recommendations from established $\mathrm{HCI}$ style guides were grouped in the same manner. To obtain the HTML style recommendations, 21 WWW sites offering recommendations regarding HCI components of HTML were identified in the fall of 1995. From these reviews, a set of 357 unique style recommendations were obtained. Recommendations from established HCI style guides were collected from five printed sources, with all recommendations not applicable to HTML discarded. For this sample, style guides were excluded if specific to a given platform or operating system. This review resulted in a collection of 270 unique style recommendations.

\section{CHARACTERIZATION}

Characterization of $\mathrm{HCI}$ style guides for HTML first looked at the frequency at which specific recommendations were cited. The majority of the 357 recommendations (269 or $75 \%$ ) appeared in only one style guide. Next, each recommendation was assigned to one of 20 categories. Figure 1 shows the distribution of recommendations across categories. Four categories accounted for $63 \%$ of the recommendations: Common Look and Feel (CL\&F), Information Display, Navigation and Labels.

\section{COMPARISON WITH ESTABLISHED HCI STYLE GUIDES}

The comparison of HTML and established HCl style guides began with a consideration of the development process. Ten authors of HCI style guides, $5 \mathrm{HTML}$ and 5 established, were surveyed. Surveys revealed distinct differences. All HTML style guide authors were from educational environments and described the development process as informal with an average of 3.26 weeks spent writing the style guide, with revisions prompted by feedback from users or impending conference submissions. In contrast, none of the established style guide authors were from educational domains, but from military, government and corporate organizations. Three of five specified that a formal process was employed to develop 
the style guide, with an average of 54.2 weeks for the initial version, with subsequent versions following annual reviews and structured working groups.

As shown in Figure 1, the categorization of recommendations reveals some overlap, but also considerable differences between HTML and established style guides. A Chi Square test of independence showed a significant difference in the distributions of recommendations across categories $\left(X^{2}=245.5\right.$, $p<0.05 ; \mathrm{df}=19$ ). The biggest differences arise from the greater concern for information display and consideration of help, data entry and message boxes within established HCI style guides. The next comparison assessed the degree to which established HCI style recommendations were addressed within HTML style guides. Of the 270 HTML-relevant recommendations found in the established HCI style guides, only $53(20 \%)$ also appeared within HTML style guides, with another 20 partially addressed within the HTML style guides. The greatest overlap occurred for recommendations categorized as common look and feel (15 of 16), menu design (11 of 17) and labels (15 of 25).

Figure 1. Distribution of Style Guide Recommendations Across Categories

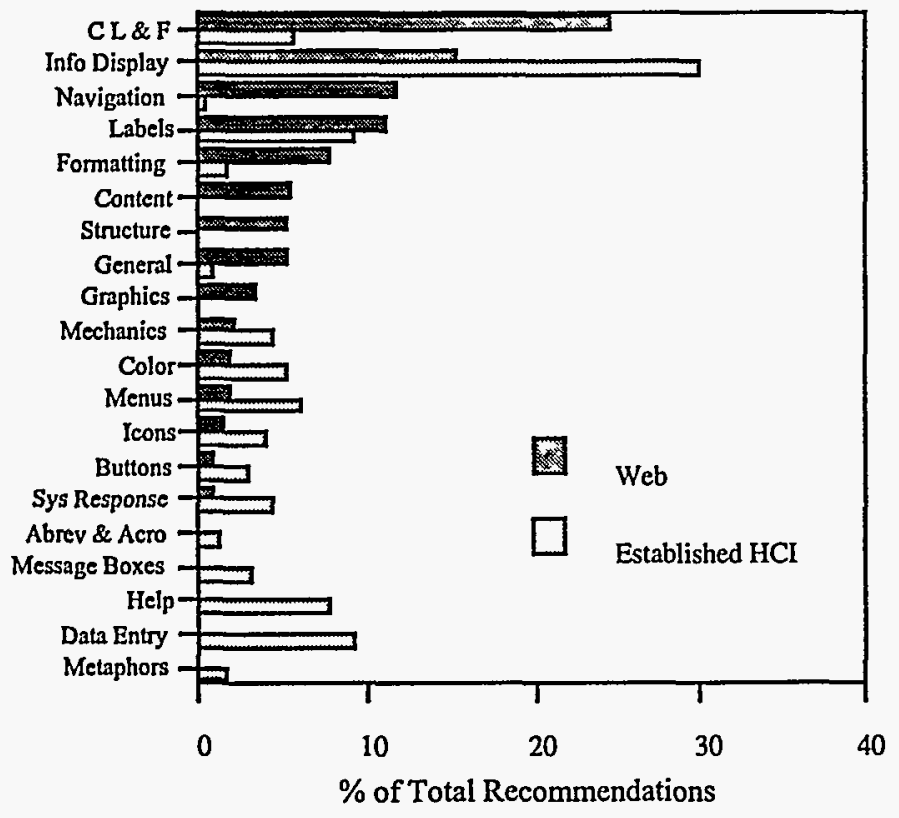

\section{ASSESSMENT}

As a further assessment of web style guides, user interface design reviews conducted by human factors practitioners at Sandia National Laboratories (SNL) for a web-based, corporate information infrastructure were evaluated to determine the extent to which findings were addressed within HTML style guides. While reviewers were knowledgeable of the established HCI style guides, all reviews occurred prior to exposure to any of the HTML style guides. Findings were drawn from two separate sets of reviews. In the first, reviewers assessed web-based applications with HTML-based HCIs. Some of the applications included were an electronic phone book, tools for accessing financial databases, and a conference room scheduler. The second set of reviews assessed pages on the SNL corporate web with purely information content (e.g., corporate newsletters, engineering procedures, departmental home pages, etc.). In the review of web-based applications only 57 of $141(40 \%)$ findings addressed HCI components discussed in the HTML style guides. In contrast, for web pages with primarily information content, 38 of $59(64 \%)$ findings were addressed within HTML style guides.

\section{CONCLUSION}

These findings reveal distinct differences in the development and content of HTML and established $\mathrm{HCl}$ style guides. Two explanations may be offered for this result. First, it may be argued that while there are overlaps, HTML introduces unique HCI concerns. This explanation is supported by the emphasis placed on common look and feel within HTML style guides. It seems reasonable to suppose that with the breadth of the WWW, where users may readily move between unrelated sites, common look and feel is of greater importance than with software applications where the primary concern is with commonality of lay-out and function, and maybe transfer of training between applications. When only information content web pages were considered, HTML style guides accounted for $64 \%$ of findings, which is as good as might be expected $[3,5]$. The second explanation would assert that HTML style guide development has occurred with less rigor and little reference to established $\mathrm{HCI}$ style guides and principles. This assertion is supported by the relatively brief development cycles for HTML style guides and the relative lack of reference to traditional HCI sources, among authors of HTML style guides. Support also comes from the neglect of applications issues and failure to account for findings obtained with webbased applications. However, it may be noted that the limited scope of HTML style guides could benefit their usability [4].

\section{ACKNOWLEDGMENT}

This work was supported by the United States Department of Energy under Contract DE-AC04-95/AL85000.

\section{REFERENCES}

1. Bodart, F. \& Vanderdonckt, J. M. Expressing Guidelines into an Ergonomic Stylegide for Highly Interactive Applications. in Proc. ACM INTERCHI'93 Human Factors in Computing Systems. (1993), 35-36.

\section{December, J \& Randall, N. The World Wide Web} Unleashed. Sams, Indiana, 1994.

3. Lowgren, J. \& Lauren, Ul. Supporting the Use of Guidelines and Style Guides in Professional User Interface Design. Interacting with Computers. 5,4 (Dec. 1993), 385-396.

4. Tetzlaff, L. \& Schwartz, D. R. The Use of Guidelines in Interface Design. in Proc. CHI'90 Human Factors in Computing Systems, (1990), 329-333.

5. Thovtrup, H. \& Nielsen, J. Assessing the Usability of a User Interface Standard. in Proc. ACM CHI'91 Human Factors in Computing Systems, (1991), 335-341. 


\section{DISCLAIMER}

This report was prepared as an account of work sponsored by an agency of the United States Government. Neither the United States Government nor any agency thereof, nor any of their employees, makes any warranty, express or implied, or assumes any legal liability or responsibility for the accuracy, completenesis, or usefuiness of any information, apparatus, product, or process disclosed, or represents that its use would not infringe privately owned rights Reference herein to any specirie commercial produch, process, or service by trade aame, trademark, manufac: turer, or otherwise does not necessarify constitute or imply its eadorsement, recommendation, or favoring by the United States Governmeat or any agency thereof. The views and opinions of authors expressed berein do not necessarily state or reflect those of the United States Governmeat or any ageacy thereof. 